\title{
Ecological remote sensing image monitoring method for vegetation destruction in waterfront greenway based on genetic algorithm
}

\author{
Jihua Liang ${ }^{*}, 1$ Jianzhong $\mathrm{Gu}^{2}$ and Naini Qiao ${ }^{1}$ \\ ${ }^{1}$ Department of Agriculture and Economics, Changde Vocation Technical College, Changde 415000, China \\ ${ }^{2}$ College of Civil Engineering, Hunan University of Arts and Science, Changde 415000, China \\ Received: 02/07/2020, Accepted: 06/08/2020, Available online: 22/10/2020 \\ *to whom all correspondence should be addressed: e-mail: jihualiang521@126.com \\ https://doi.org/10.30955/gnj.003391
}

\section{Graphical abstract}

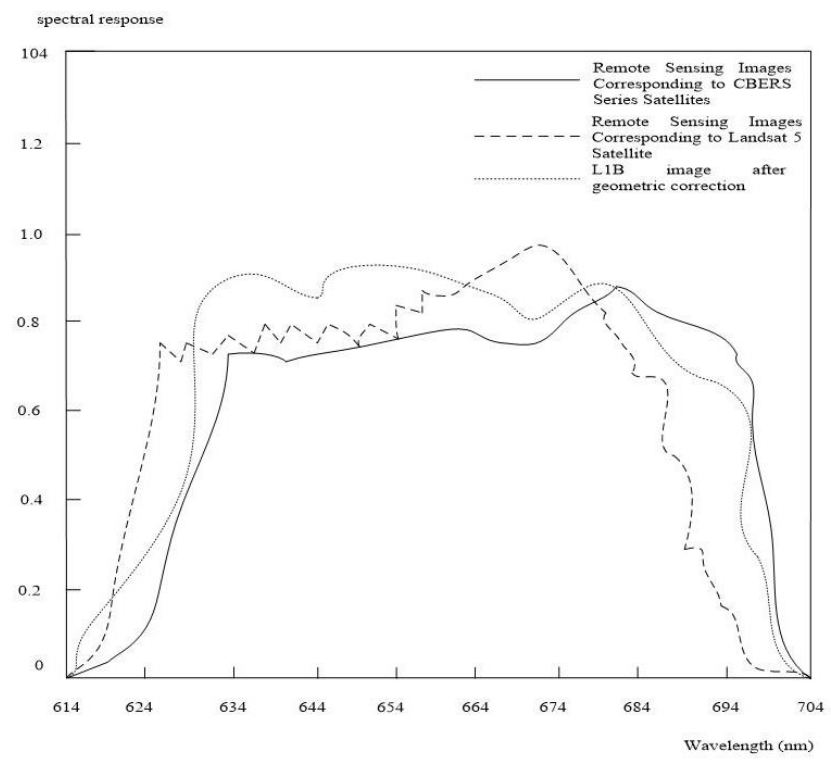

\begin{abstract}
Because the traditional remote sensing image monitoring method has the problem of poor ability of capturing vegetation destruction, an ecological remote sensing image method for vegetation destruction in waterfront greenway based on genetic algorithm is proposed. The vegetation index data of waterfront greenway were acquired by remote sensing image, and the pseudo color image was synthesized. The on orbit radiometric calibration and geometric precision correction are carried out for the collected data, and the relationship between vegetation index and vegetation damage of waterfront greenway is analyzed, including meteorological factors, geographical factors and vegetation damage of waterfront greenway. Select the independent variables of the model, establish the ecological remote sensing image monitoring model of the vegetation damage of the waterfront greenway, and realize the ecological remote sensing image monitoring of the vegetation damage of the waterfront
\end{abstract}

greenway. The experimental results show that the acquisition ability of the method based on genetic algorithm is better than that of the traditional method, and it is more suitable for the ecological remote sensing monitoring of the vegetation damage of waterfront greenway.

Keywords: Genetic algorithm, waterfront greenway, vegetation destruction, ecological remote sensing, image monitoring, WFI data, surface vegetation reflectance.

\section{Introduction}

Waterfront greenway refers to a kind of linear green corridor or green open space, which is located along the waterfront. It combines aesthetic, cultural, recreational, ecological and other functional objectives. It is an important measure to manage, plan and design the land in the waterfront area, and realize the coordinated utilization and sustainable utilization of the land in the waterfront area (Ahmadybirgani et al., 2017; Olanmilekan et al., 2019). Because waterfront greenway has the characteristics of multi-dimension and multi-scale, it can not only develop and protect cultural landscape and ecological landscape, but also improve and protect the ecological environment in the waterfront region, providing education, leisure and recreation, ecological and other functions for the region. The waterfront greenway can be divided into coastal greenway, lakeside greenway and riverside greenway from the crossing area. Coastal greenway refers to the greenway that mainly crosses the ocean and faces the ocean; lakeside greenway refers to the greenway that mainly crosses the lake and faces the lake; riverside greenway refers to the greenway that mainly crosses the river and faces the river, which is influenced by the area of the water area, and riverside greenway is the main construction type of the waterfront greenway (Almada et al., 2017). From the view attribute, waterfront greenway can be divided into mixed waterfront greenway, historical waterfront greenway and natural waterfront greenway. Among them, the mixed waterfront greenway refers to the waterfront greenway which mixes the cultural and natural functions, that is, the 
cultural and historical landscape along the line and the natural landscape are more developed; the historical waterfront greenway refers to the waterfront greenway where the cultural and historical landscape are mainly distributed along the line; and the natural waterfront greenway refers to the waterfront greenway where the natural landscape is mainly distributed along the line. From the specific location, waterfront greenway can be divided into urban waterfront greenway, suburban waterfront greenway and ecological waterfront greenway (Kanule and Ng'etich, 2020; Liu, 2018). Among them, urban waterfront greenway refers to the greenway laid mainly by urban areas for the purpose of facilitating residents to go out for activities and improving their living environment; suburban waterfront greenway refers to the greenway laid mainly by suburbs for the convenience of urban residents to go to the suburbs for recreation, to connect urban and rural ecology, which is the greenway laid out in the suburbs; and the ecological waterfront greenway refers to a greenway that protects coastal biodiversity and ecological environment and facilitates natural scenery viewing. It is mainly distributed in rural areas (Emaminejad et al., 2017). From the functional point of view, waterfront greenway can be divided into leisure tourism waterfront greenway, heritage protection waterfront greenway and ecological waterfront greenway. Many waterfront greenways often have multiple types and functions at the same time, bearing a heavy historical connotation. However, in recent years, the vegetation of waterfront greenway has been damaged repeatedly. In order to ensure the connectivity and integrity of the ecological function of waterfront greenway, it is necessary to monitor the vegetation destruction of waterfront greenway by remote sensing image.

Some foreign scholars put forward a remote sensing image monitoring method for vegetation destruction in waterfront greenway based on spectral characteristics of vegetation, mainly through analyzing the spectral characteristics of remote sensing image of vegetation in waterfront greenway to achieve ecological remote sensing image monitoring of vegetation destruction; and some scholars put forward a remote sensing image monitoring method for vegetation destruction in waterfront greenway

Table 1. Specific spectral range for each spectral band of CCD data based on weak classifier of decision tree. Through the weak classifier of decision tree, the remote sensing image of vegetation destruction in waterfront greenway is classified and monitored by decision-making. In China, some scholars put forward a remote sensing image monitoring method for vegetation destruction in waterfront greenway based on vegetation extraction algorithm, which extracts the remote sensing image of vegetation destruction in waterfront greenway mainly through vegetation extraction algorithm, so as to realize the remote sensing of vegetation destruction. Some scholars also propose a remote sensing image monitoring method based on manual threshold method for vegetation destruction in waterfront greenway. The slope of remote sensing image of vegetation destruction in waterfront greenway is divided by manual threshold method, so as to realize the ecological remote sensing image monitoring of vegetation destruction (Emanuel and Emest, 2020; Graf et al., 2017). In view of the shortcomings of these traditional remote sensing image monitoring methods for vegetation destruction in waterfront greenways, a method based on genetic algorithm for monitoring vegetation destruction in waterfront greenways is proposed.

\section{Material and methods}

\subsection{Acquisition of ecological remote sensing image data of vegetation destruction in waterfront greenway}

\subsubsection{Acquisition of ecological remote sensing image data}

WFI data is used as the main data source of ecological remote sensing image data of vegetation destruction in waterfront greenway (Grezzana et al., 2017). WFI data are remote sensing wide field of view data obtained by WFI sensors on CBERSO2B satellite, CBERSO2 satellite, CBERSO1 satellite and Landsat5 satellite, including $C C D$ data and TM data (Govindan and Annamalai, 2019; Kang et al., 2018). Among them, there are five spectral bands for CCD data, one is near infrared band and the other four are visible bands. The data width can reach more than 100 kilometers and the resolution can reach more than 20 meters. The specific spectral range of each spectral band is shown in Table 1.

\begin{tabular}{|c|c|c|c|c|}
\hline Satellite & Band number & Sensor & Spatial resolution $(\mathrm{m})$ & Spectral range $(\mu \mathrm{m})$ \\
\hline \multirow{2}{*}{ CBERS01 satellite } & B01 & \multirow{5}{*}{ CCD Camera } & 20 & $0.45-0.52$ \\
\hline & B02 & & 20 & $0.52-0.59$ \\
\hline CBERSO2 satellite & B03 & & 20 & $0.63-0.69$ \\
\hline \multirow{2}{*}{ CBERS02B satellite } & B04 & & 20 & 0.77-0.89 \\
\hline & B05 & & 20 & $0.51-0.73$ \\
\hline Satellite & Band number & Sensor & Spatial resolution (m) & Spectral range $(\mu \mathrm{m})$ \\
\hline \multirow{7}{*}{ Landsat 5 satellite } & B1 & \multirow{7}{*}{ TM Theme Imager } & 30 & $0.45-0.52$ \\
\hline & B2 & & 30 & $0.52-0.60$ \\
\hline & B3 & & 30 & $0.63-0.69$ \\
\hline & B4 & & 30 & $0.76-0.90$ \\
\hline & $\mathrm{B} 5$ & & 30 & $1.55-1.75$ \\
\hline & B6 & & 120 & $10.40-12.50$ \\
\hline & B7 & & 30 & $2.08-2.35$ \\
\hline
\end{tabular}


TM data can be divided into seven bands. Its data width can reach more than 180 kilometers and resolution can reach more than 30 meters. The specific spectral range of each spectral band is shown in Table 2 .

Table 3. Specific classification criteria for vegetation coverage

\begin{tabular}{cccc}
\hline Level & Level & Description of landscape comprehensive characteristics & Major territories \\
\hline Higher coverage & Level five & $\begin{array}{r}\text { Vegetation coverage is more than } 80 \% \text {, plant biomass is } \\
\text { very high, and there is no desertification. }\end{array}$ & $\begin{array}{c}\text { Arable land, forest and high- } \\
\text { cover grassland areas }\end{array}$ \\
\hline High coverage & Level four & $\begin{array}{c}\text { Vegetation coverage is more than } 50 \%-80 \% \text {, plant } \\
\text { biomass is high, and there is no desertification basically. }\end{array}$ & $\begin{array}{c}\text { Farmland, Wetland and High } \\
\text { Covered Grassland Areas }\end{array}$ \\
\hline Medium coverage & Level three & $\begin{array}{r}\text { Vegetation coverage is } 30 \%-50 \%, \text { plant biomass is } \\
\text { moderate and desertification is low. }\end{array}$ & $\begin{array}{c}\text { Grassland vegetation area and } \\
\text { mild desertification farmland } \\
\text { area }\end{array}$ \\
\hline Low coverage & $\begin{array}{c}\text { second } \\
\text { level }\end{array}$ & $\begin{array}{c}\text { Vegetation coverage ranges from } 10 \% \text { to } 30 \%, \text { plant } \\
\text { biomass is low and desertification is serious. }\end{array}$ & $\begin{array}{c}\text { Severe saline-alkali areas with a } \\
\text { small amount of vegetation }\end{array}$ \\
\hline Lower coverage & Class A & $\begin{array}{c}\text { Vegetation coverage is less than } 10 \%, \text { plant biomass is } \\
\text { very low and desertification is very high. }\end{array}$ & Bare land, saline-alkali bare land \\
\hline
\end{tabular}

Table 4. Specific statistical results of vegetation coverage

\begin{tabular}{cccccccc}
\hline & Level coverage & Level five & Level Four & Level three & Second level & Class A & Total area \\
\hline \multirow{2}{*}{2016} & The measure of area & 107.86 & 1154.92 & 747.63 & 101.1 & 12.75 & 2124.26 \\
\cline { 2 - 7 } & Percentage & $5.08 \%$ & $54.37 \%$ & $35.19 \%$ & $4.76 \%$ & $0.60 \%$ & $100.00 \%$ \\
\hline \multirow{2}{*}{2017} & The measure of area & 209.7 & 1642.94 & 239.22 & 23.54 & 8.86 & 2124.26 \\
\cline { 2 - 7 } & Percentage & $9.87 \%$ & $77.34 \%$ & $11.26 \%$ & $1.11 \%$ & $0.42 \%$ & $100.00 \%$ \\
\hline \multirow{2}{*}{2018} & The measure of area & 374.78 & 1482.09 & 193.84 & 57.13 & 16.41 & 2124.26 \\
\cline { 2 - 7 } & Percentage & $17.64 \%$ & $69.77 \%$ & $9.13 \%$ & $2.69 \%$ & $0.77 \%$ & $100.00 \%$ \\
\hline \multirow{2}{*}{2019} & The measure of area & 311.12 & 1588.41 & 189.02 & 23.27 & 12.44 & 2124.26 \\
\cline { 2 - 7 } & Percentage & $14.65 \%$ & $74.77 \%$ & $8.90 \%$ & $1.10 \%$ & $0.59 \%$ & $100.00 \%$ \\
\hline
\end{tabular}

Table 5. Specific channel parameters of CBERS and Landsat 5 satellites

\begin{tabular}{ccccc}
\hline Satellite & Band width & Band & Resolving power & Central wavelength \\
\hline \multirow{2}{*}{ CBERS series satellites } & 1 & $630-690 \mathrm{~nm}$ & $258 \mathrm{~m}$ & 657.74 \\
\cline { 2 - 5 } & 2 & $770-890 \mathrm{~nm}$ & $258 \mathrm{~m}$ & 831.98 \\
\hline \multirow{2}{*}{ Landsat5 satellite } & 1 & $620-670 \mathrm{~nm}$ & $250 \mathrm{~m}$ & 646.3 \\
\cline { 2 - 5 } & 2 & $841-876 \mathrm{~nm}$ & $250 \mathrm{~m}$ & 856.48 \\
\hline
\end{tabular}

The related geographical data of vegetation in waterfront greenway are acquired, including the evapotranspiration, annual precipitation, annual accumulated temperature and other vegetation-related geographical information at each pixel in WFI remote sensing image (Clifford et al., 2019; Lehmann et al., 2017). Furthermore, latitude and longitude information of each pixel are extracted to synthesize latitude and longitude raster images. The obtained ecological remote sensing image data are all interpolated image files, and the actual pixel size is about $4 \mathrm{Km} \times 4 \mathrm{Km}$.

\subsubsection{Acquisition of vegetation distribution characteristic data}

Firstly, the vegetation index data of waterfront greenway is obtained by remote sensing sensor, which is a kind of multispectral data. It has an indication significance for vegetation growth and has timeliness and regionality (Lisón et al., 2017). A near infrared band capable of high transmission and reflection for green plants and a visible red band capable of strong absorption for green plants are selected (Zhang et al., 2017). Their spectral ranges are 0.7$1.1 \mu \mathrm{m}$ and 0.6-0.7 $\mu \mathrm{m}$, respectively. NDVI is the most suitable index to reflect the vegetation condition of waterfront greenway. The higher the NDVI index is, the smaller the degree of vegetation destruction is (Liu et al., 2019). The NDVI vegetation index is calculated in Band 2 (near infrared band0 and Band 1 (red band) from remote sensing image data. The specific formulas are as follows:

$$
\mathrm{NVDI}=\frac{\rho_{\mathrm{NIR}}-\rho_{\mathrm{R}}}{\rho_{\mathrm{NIR}}+\rho_{\mathrm{R}}}
$$

where, NVDI represents NDVI vegetation index, $\rho$ NIR represents surface vegetation reflectance after atmospheric correction, and $\rho_{R}$ represents surface vegetation coverage.

The NDVI vegetation index is modified to establish an iteration equation based on the soil vegetation regulation index. The modified NDVI vegetation index is obtained by using the iteration equation as follows:

$$
\left\{\begin{array}{l}
\mathrm{SAVI}=\frac{(\mathrm{NIR}-R)}{(\mathrm{NIR}+R+L)}(1+L) \\
\mathrm{MSAVI}=\frac{2 \mathrm{NIR}+1-\sqrt{(2 \mathrm{NIR}+1)^{2}-8(\mathrm{NIR}-R)}}{2}
\end{array}\right.
$$

where, SAVI represents the soil vegetation regulation index; MSAVI represents the modified NDVI vegetation index; NIR represents the real-time reflectance value of near-infrared light channel; $R$ represents the real-time reflectance value of visible light channel; $L$ represents a set parameter of soil regulation, and the parameters are determined by the vegetation density (Lu et al., 2017). 
After modifying NDVI vegetation index, the influence of noise in ecological remote sensing image data can be reduced.

The vegetation coverage of waterfront greenway is calculated and the quantitative linear relationship between the modified NDVI vegetation index and the vegetation coverage of waterfront greenway is established. The formula for calculating the vegetation coverage of waterfront greenway is as follows:

$$
f=\frac{\left(R-R_{\mathrm{s}}\right)}{\left(R_{\mathrm{v}}-R_{\mathrm{s}}\right)}
$$

where, $f$ represents vegetation coverage of waterfront greenway; $R \mathrm{~s}$ represents reflection radiation of vegetation; $R \vee$ represents the reflection radiation of soil.

The quantitative linear relationship between the modified NDVI vegetation index and the vegetation coverage of waterfront greenway is as follows:

$$
f=\frac{M S A V I-M S A V I_{\min }}{M_{\text {maV }}-M S A V I_{\text {min }}}
$$

where, MSAVImax represents the maximum value of MSAVI in the vegetation-covered area of waterfront greenway, and $M S A V I_{\min }$ represents the minimum value of MSAVI in the vegetation-covered area of waterfront greenway (Malkoc et al., 2017).

The spatial model of waterfront greenway is established by using the modeling module of remote sensing image processing software, and the specific calculation value of ecological remote sensing image and formula (4) of vegetation coverage of waterfront greenway are input (Mao et al., 2017). Based on the modified NDVI vegetation index, the vegetation coverage of waterfront greenway can be divided into five levels: higher coverage, high coverage, medium coverage, low coverage and lower coverage. The criteria are shown in Table 3.

The vegetation coverage area of waterfront greenway is calculated by using the classification standard of the above table. The specific statistical results are shown in Table 4.

\section{Processing of ecological remote sensing image for vegetation destruction in waterfront greenway}

\subsection{Pseudo-color image synthesis}

After obtaining the ecological remote sensing image data and the vegetation distribution characteristic data, the data are made pseudo-color image synthesis processing (Mehl, 2017). Firstly, the image's green band, near infrared band and red band are generated by calibration coefficients, and the RGB band is combined in the order of green band, red band and near infrared band. Then the MSAVI is standardized. The processing method is as follows:

$$
\mathrm{DN}_{\mathrm{MSAVI}}=(\mathrm{MSAVI}+1) * 100
$$

where DNMSAVI represents the standardized result of MSAVI.
Finally, the first band of ecological remote sensing image data and vegetation distribution characteristics data is set as red channel, the second band as blue channel, and the third band as green channel to achieve pseudo-color image synthesis (Onamuti et al., 2017).

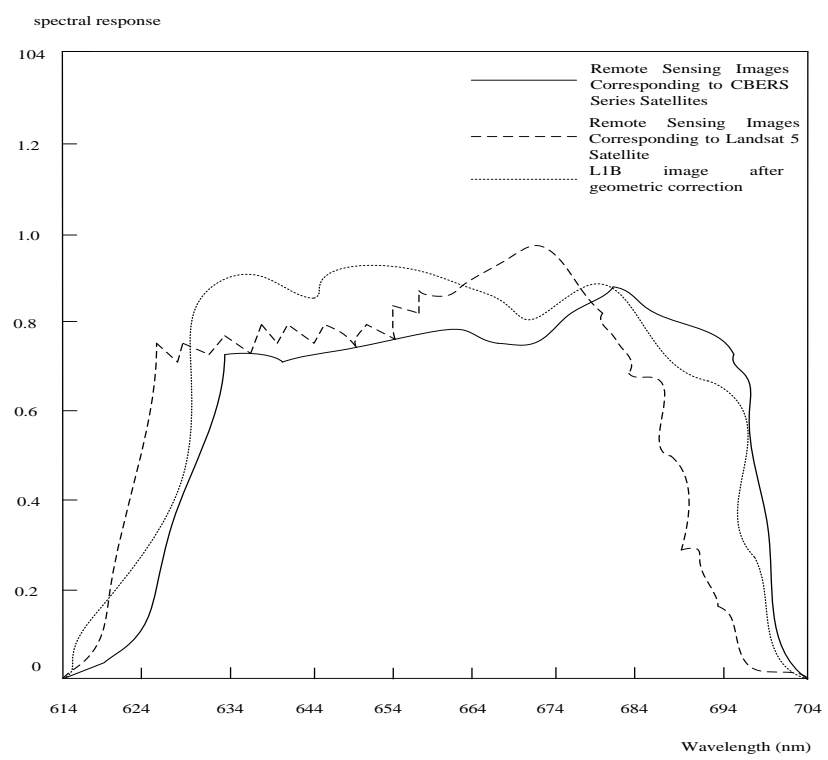

Figure 1. Spectral response function in Channel 1

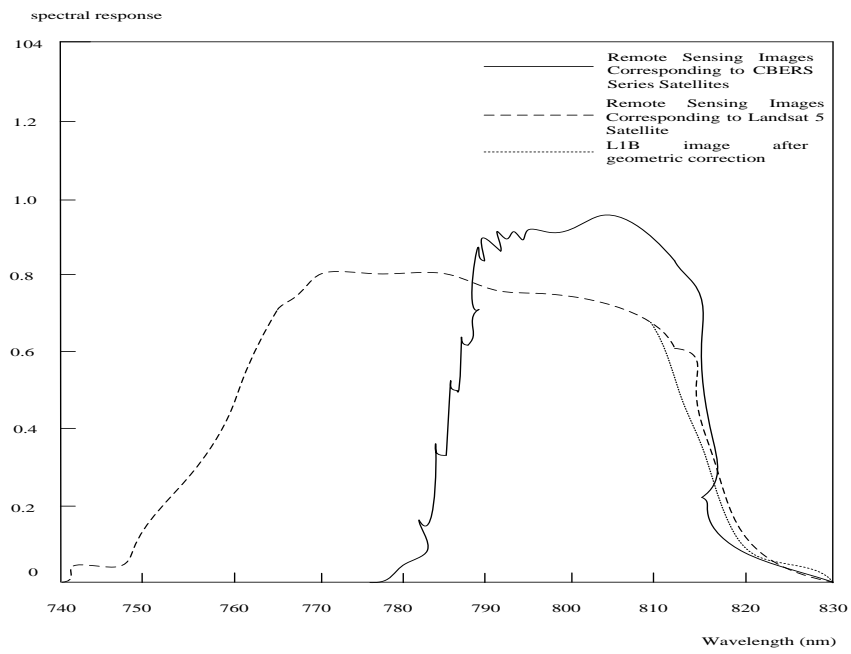

Figure 2. Spectral response function in Channel 2

\subsection{In-orbit radiometric calibration of data}

In-orbit radiometric calibration of data is carried out using MODIS sensor. The edge data of MODIS sensor images are removed, the L1B data of the second and first bands of MODIS data are geometrically corrected, and the resolution of image is resampled by the nearest neighborhood method (Wang et al., 2018). The remote sensing image corresponding to CBERS and Landsat5 satellites is matched with the L1B image after geometrically corrected, the matching error is controlled, and the spectral response is implemented separately (Stefani et al., 2018). The channel parameters of CBERS and Landsat5 satellites are shown in Table 5.

The spectral response functions of remote sensing images corresponding to CBERS and Landsat 5 satellites and geometrically corrected L1B images in Channel 1 and Channel 2 are shown in Figures 1 and 2, respectively. 


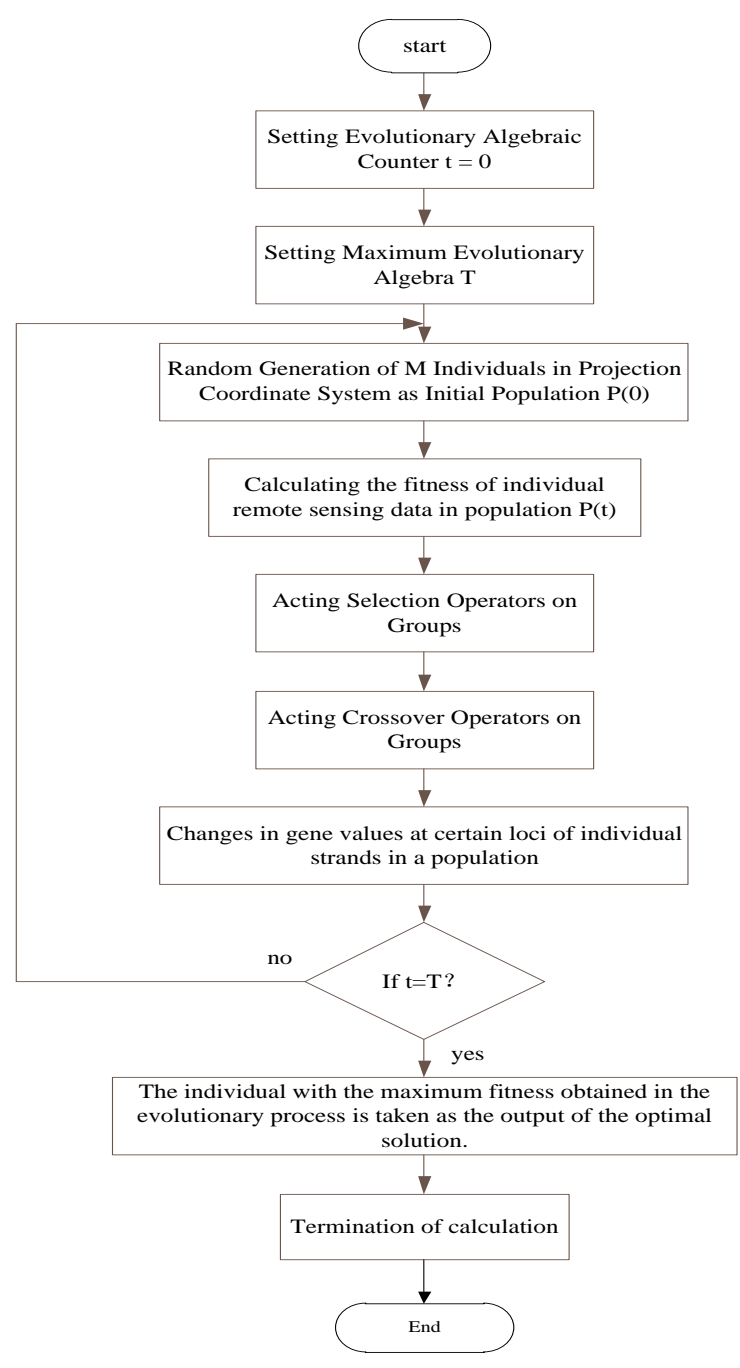

Figure 3. Specific flow chart of orthodontic treatment

Spectral response data is used to make in-orbit radiometric calibration, and the specific calibration formulas are as follows:

$$
\left\{\begin{array}{l}
D C_{w i}=\frac{\rho_{w i}}{\rho_{m i}} \cdot \frac{E_{w s i} \cdot \cos \theta_{w}}{\pi \cdot d^{2}} \cdot \frac{1}{C_{m i}} D C_{m i} \cdot a_{w i}+D C_{w 0, i} \\
D C_{w s i}=\frac{\rho_{w i}}{\rho_{m i}} \cdot \frac{1}{C_{m i}} \cdot D C_{m i} \cdot c_{w i}+D C_{w 0, i}
\end{array}\right.
$$

where, $D_{\text {wi }}$ represents the radiance of WFI remote sensing image; $D C_{w s i}$ represents the apparent reflectance of WFI remote sensing image; $\rho_{w i} / \rho_{m i}$ represents the spectral matching factor corresponding to the two channels of MODIS sensor; $\rho_{w i}$ represents the apparent reflectance of WFI remote sensing image data (Liu and Baghban, 2017); $\rho_{\text {mi }}$ represents the apparent reflectance of MODIS sensor data; $E_{w s i}$ represents the solar equivalent irradiance at the average solar-terrestrial distance; $\theta_{w}$ represents zenith solar angle when WFI remote sensing image is over the zenith; $d$ represents average solar-terrestrial distance; $\left(E_{w s i} \cdot \cos \theta_{w} / \pi \cdot d^{2}\right)$ represents the difference correction result of solar equivalent irradiance when MODIS sensor is over the zenith; $c_{m i}$ represents the calibration coefficient of sensor channel of TAO reflectance; $\mathrm{DC}_{m i}$ represents the counting value of MTAOODIS sensor data; $a_{\text {wi }}$ represents the radiance in the channel $i$ of the MODIS sensor; $\mathrm{DC}_{w 0, \mathrm{i}}$ represents the overall offset of the counting value in channel $i$ of the MODIS sensor; $c_{w i}$ represents the overall gain coefficient of the apparent reflectance in channel $i$ of the MODIS sensor.

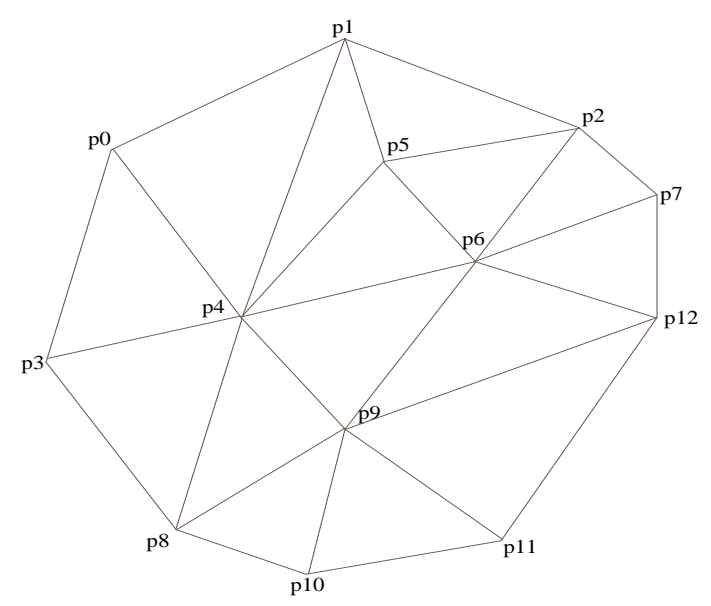

Figure 4. Specific schematic diagram of the triangular network composition

The results of in-orbit radiometric calibration are shown in Table 6.

\subsection{Geometric precision correction of data}

Geometric precise correction of remote sensing image data and vegetation distribution characteristics data is carried out based on genetic algorithm. Firstly, the remote sensing data are orthodontically processed by genetic algorithm, so that the data can be placed in the projection coordinate system. The specific process of orthodontic processing is shown in Figure 3.

After orthodontic treatment, the data in projection coordinate system is corrected by triangulation correction method, which includes three steps: selecting control points, transforming coordinates and resampling pixels (Liu et al., 2010; Prabal and Rahman, 2020). Firstly, the control points are selected accurately and formed into a triangular network. The specific schematic diagram is shown in Figure 4.

Then the coordinates are transformed by the coordinate linear transformation equation. The coordinate transformation equation is as follows:

$$
\left\{\begin{array}{l}
X_{0}=a_{0}+a_{1} x+a_{2} y \\
Y_{0}=b_{0}+b_{1} x+b_{2} y
\end{array}\right.
$$

where, $X_{0}$ and $Y_{0}$ represent the converted abscissa and ordinate coordinates, $x$ and $y$ represent the abscissa and ordinate coordinates before conversion, $a_{0}, a_{1}$ and $a_{2}$ represent the abscissa conversion coefficients of coordinate linear transformation equation, and $b_{0}, b_{1}$ and $b_{2}$ represent the longitudinal conversion coefficients of coordinate linear transformation equation.

After completing the coordinate transformation, the result graph can be obtained. In the triangle of the image, each vertex is corrected separately (Oyekale, 2017). The 
correction coefficient needs to be determined according to the size of the triangle to achieve the geometric correction of the data.

Table 6. Final data obtained from on-orbit radiometric calibration

\begin{tabular}{ccc}
\hline Index & Band 1 & Band 2 \\
\hline Radiance calibration coefficient & 2.24 & 1.63 \\
\hline Calibration coefficient of apparent reflectance & 1106.6 & 496.53 \\
\hline Offset (DNs) & -2.40 & 4.52 \\
\hline
\end{tabular}

Table 7. Correlation coefficient between vegetation index and vegetation destruction in waterfront greenway

\begin{tabular}{cc}
\hline \multicolumn{2}{c}{ The correlation coefficient between vegetation index and vegetation destruction in waterfront Greenway } \\
\hline $2017 \mathrm{WFI}-N D V I$ & 0.256 \\
\hline $2018 \mathrm{WFI}-N D V I$ & 0.204 \\
\hline $2017 \mathrm{MODIS-NDVI}$ & 0.207 \\
\hline
\end{tabular}

Table 8. Analysis of variance between vegetation index and vegetation destruction in waterfront greenway

\begin{tabular}{|c|c|c|c|c|c|c|}
\hline Data type & & Sum of squares & Average sum of squares & Freedom & $\mathbf{F}$ & $\begin{array}{c}\text { Critical } \\
\text { value }\end{array}$ \\
\hline \multirow{3}{*}{ 2017WFI-NDVI } & Regression & 463348.935 & 463348.935 & 1 & \multirow{3}{*}{143.955} & \multirow{3}{*}{0.000} \\
\hline & Residual & 6608004.819 & 3218.707 & 2053 & & \\
\hline & Total & 7071353.754 & & 2054 & & \\
\hline \multirow{3}{*}{ 2018WFI-NDVI } & Regression & 8272.779 & 8272.779 & 1 & \multirow{3}{*}{72.405} & \multirow{3}{*}{0.121} \\
\hline & Residual & 7063080.975 & 3440.371 & 2053 & & \\
\hline & Total & 7071353.754 & & 2054 & & \\
\hline \multirow{3}{*}{$\begin{array}{l}\text { 2017MODIS- } \\
\text { NDVI }\end{array}$} & Regression & 303605.468 & & 1 & \multirow{3}{*}{92.099} & \multirow{3}{*}{0.000} \\
\hline & Residual & 6767748.286 & 303605.468 & 2053 & & \\
\hline & Total & 7071353.754 & 3296.516 & 2054 & & \\
\hline
\end{tabular}

Table 9. The relationship among meteorological factors, geographic factors and vegetation destruction in waterfront greenways

\begin{tabular}{ccc}
\hline Independent variable & Type & $\begin{array}{c}\text { Coefficient of correlation with vegetation destruction in waterfront } \\
\text { Greenway }\end{array}$ \\
\hline Latitude & Geographical factors & -0.206 \\
\hline Accuracy & Geographical factors & 0.221 \\
\hline Actual evapotranspiration & Meteorological factors & 0.237 \\
\hline Relative evapotranspiration & Meteorological factors & 0.212 \\
\hline Wettability & Meteorological factors & 0.181 \\
\hline Temperature & Meteorological factors & 0.078
\end{tabular}

\section{Realization of remote sensing image monitoring of vegetation destruction in waterfront greenway}

\subsection{Selection of independent variables}

After processing the remote sensing image data of vegetation destruction in waterfront greenway, the correlation between vegetation index and vegetation destruction in waterfront greenway is analyzed. The results are shown in Tables 7 and 8.

Then, the relationship among meteorological factors, geographical factors and vegetation destruction in waterfront greenway is analyzed. The results are shown in Table 9.

The results of comprehensive correlation analysis of the above independent variables are shown in Figure 5.

4.2. Establishment of remote sensing image monitoring model for vegetation destruction in waterfront greenway

Based on the comprehensive correlation analysis of independent variables, a remote sensing image monitoring model for vegetation destruction in waterfront greenway is established (Deymi-Dashtebayaz and KazemianiNajafabad, 2019). The remote sensing image monitoring model for vegetation destruction in waterfront greenway includes seven multiple linear regression models, as shown in Table 10.

\section{Results}

\subsection{Experimental process}

In order to test the performance of the proposed remote sensing image monitoring method for vegetation destruction in waterfront greenway based on genetic algorithm, a comparative experiment is carried out. The remote sensing image monitoring of vegetation destruction in a waterfront greenway is selected to collect the data of 2017 WFI-NDVI, 2018 WFI-NDVI, 2017 MODISNDVI, latitude, longitude, actual evapotranspiration, relative evapotranspiration, humidity, temperature and other independent variables of the waterfront greenway. The average square sum of the corrected data is shown in Figure 6 based on genetic algorithm. 
The square sum of the corrected data is substituted into seven multiple linear regression models for remote sensing image monitoring model of vegetation destruction in waterfront greenway, and the remote sensing image monitoring of vegetation destruction in waterfront greenway is carried out. In order to ensure the validity of this experiment, the remote sensing image monitoring method for vegetation destruction in waterfront greenway based on spectral characteristics of vegetation (Yevdokimov et al., 2019), the remote sensing image monitoring method for vegetation destruction in waterfront greenway based on weak classifier of decision tree, the remote sensing image monitoring method for vegetation destruction in waterfront greenway based on vegetation extraction algorithm, and the remote sensing image monitoring method for vegetation destruction in waterfront greenway based on manual threshold method are used to compare with the ecological remote sensing image monitoring method for vegetation destruction in waterfront greenway based on genetic algorithm proposed in this paper (Kumar, 2017). The experimental results show that when comparing the vegetation destruction capturing power of each remote sensing image monitoring method for vegetation destruction in waterfront greenway, the effect of vegetation destruction capturing power is graded from 1 to 10 , and the higher the series is, the stronger the vegetation destruction capturing power of the ecological remote sensing image monitoring method is, that is to say, it can capture vegetation destruction of waterfront greenway more finely.

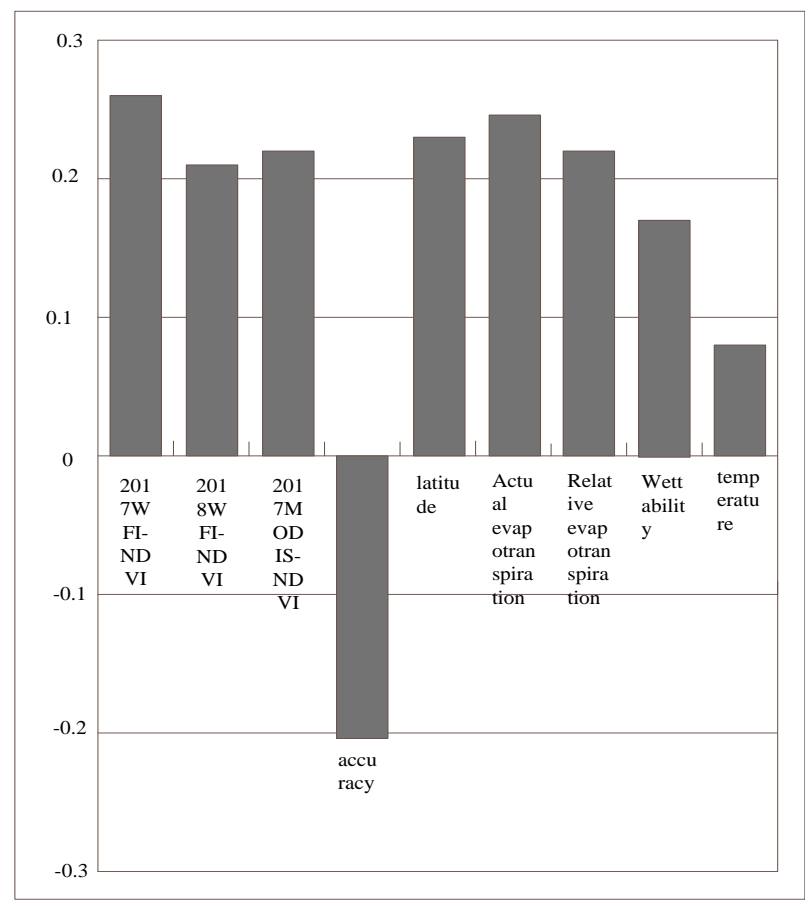

Figure 5. Comprehensive correlation analysis of independent variables

\subsection{Experimental results}

Image monitoring method based on vegetation spectral features, image monitoring method based on weak classifier of decision tree, image monitoring method based on vegetation extraction algorithm, image monitoring method based on manual threshold method, image monitoring method based on genetic algorithm are used to monitor the ecological remote sensing images of vegetation destruction in waterfront greenway, and the results of the vegetation destruction capturing power experiments of each model are shown in Table 11.

The experimental results of vegetation destruction capturing ability of each method are shown in Table 12 .

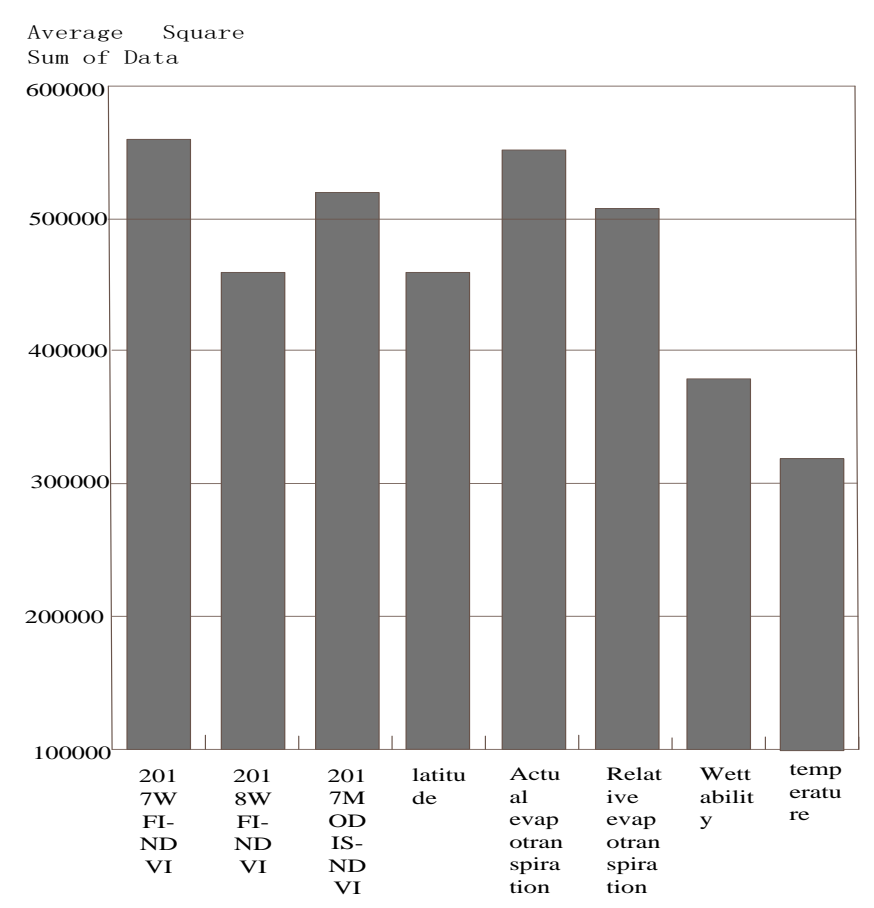

Figure 6. Mean square of corrected data

According to the experimental results of each method in Table 12, the capturing power of vegetation destruction of remote sensing image monitoring method based on spectral characteristics of vegetation is 6; the capturing power of vegetation destruction of remote sensing image monitoring method based on weak classifier of decision tree is 7; the capturing power of vegetation destruction of image monitoring method based on vegetation extraction algorithm is 5; and the capturing power of image monitoring based on manual threshold method is 6 ; the capturing power of vegetation destruction of remote sensing image monitoring method based on genetic algorithm is 9. That is to say, the capturing power of vegetation destruction of remote sensing image monitoring method based on genetic algorithm is higher than that of traditional remote sensing image monitoring methods.

\section{Conclusions}

The remote sensing image monitoring method for vegetation destruction in waterfront greenway based on genetic algorithm improves the capturing power of vegetation destruction in traditional methods, which has 
great reference significance for the overall monitoring and actual vegetation restoration of waterfront greenway.

Table 10. Establishment of remote sensing image monitoring model for vegetation destruction in waterfront greenway

\begin{tabular}{|c|c|c|c|c|c|c|c|}
\hline Model & $\begin{array}{l}\text { Multivariate } \\
\text { linear } \\
\text { regression } \\
\text { model } 1\end{array}$ & $\begin{array}{l}\text { Multivariate } \\
\text { linear } \\
\text { regression } \\
\text { model } 2\end{array}$ & $\begin{array}{l}\text { Multivariate } \\
\text { linear } \\
\text { regression } \\
\text { model } 3\end{array}$ & $\begin{array}{l}\text { Multivariat } \\
\text { e linear } \\
\text { regression } \\
\text { model } 4\end{array}$ & $\begin{array}{l}\text { Multivariate } \\
\text { linear } \\
\text { regression } \\
\text { model } 5\end{array}$ & $\begin{array}{l}\text { Multivariate } \\
\text { linear } \\
\text { regression } \\
\text { model } 6\end{array}$ & $\begin{array}{l}\text { Multivariate } \\
\text { linear } \\
\text { regression } \\
\text { model } 7\end{array}$ \\
\hline $\begin{array}{c}\text { Dependent } \\
\text { variable }\end{array}$ & $\begin{array}{c}\text { Vegetation } \\
\text { destruction in } \\
\text { waterfront } \\
\text { Greenway }\end{array}$ & $\begin{array}{l}\text { Vegetation } \\
\text { destruction in } \\
\text { waterfront } \\
\text { Greenway }\end{array}$ & $\begin{array}{c}\text { Vegetation } \\
\text { destruction in } \\
\text { waterfront } \\
\text { Greenway }\end{array}$ & $\begin{array}{c}\text { Vegetation } \\
\text { destruction } \\
\text { in } \\
\text { waterfront } \\
\text { Greenway }\end{array}$ & $\begin{array}{l}\text { Vegetation } \\
\text { destruction in } \\
\text { waterfront } \\
\text { Greenway }\end{array}$ & $\begin{array}{l}\text { Vegetation } \\
\text { destruction in } \\
\text { waterfront } \\
\text { Greenway }\end{array}$ & $\begin{array}{l}\text { Vegetation } \\
\text { destruction } \\
\text { in } \\
\text { waterfront } \\
\text { Greenway }\end{array}$ \\
\hline $\begin{array}{c}\text { Independent } \\
\text { variable } 1\end{array}$ & Longitude & Longitude & Longitude & Longitude & Longitude & Longitude & Longitude \\
\hline $\begin{array}{c}\text { Independent } \\
\text { variable } 2\end{array}$ & $\begin{array}{c}\text { Actual } \\
\text { evapotranspir } \\
\text { ation }\end{array}$ & $\begin{array}{c}\text { Actual } \\
\text { evapotranspir } \\
\text { ation }\end{array}$ & $\begin{array}{c}\text { Actual } \\
\text { evapotranspir } \\
\text { ation }\end{array}$ & $\begin{array}{c}\text { Actual } \\
\text { evapotransp } \\
\text { iration }\end{array}$ & $\begin{array}{c}\text { Actual } \\
\text { evapotranspirat } \\
\text { ion } \\
\end{array}$ & $\begin{array}{c}\text { Actual } \\
\text { evapotranspir } \\
\text { ation }\end{array}$ & $\begin{array}{c}\text { Actual } \\
\text { evapotranspi } \\
\text { ration } \\
\end{array}$ \\
\hline $\begin{array}{c}\text { Independent } \\
\text { variable } 3\end{array}$ & $\begin{array}{c}\text { Relative } \\
\text { evapotranspir } \\
\text { ation }\end{array}$ & $\begin{array}{c}\text { Relative } \\
\text { evapotranspir } \\
\text { ation }\end{array}$ & $\begin{array}{c}\text { Relative } \\
\text { evapotranspir } \\
\text { ation }\end{array}$ & $\begin{array}{c}\text { Relative } \\
\text { evapotransp } \\
\text { iration }\end{array}$ & $\begin{array}{c}\text { Relative } \\
\text { evapotranspirat } \\
\text { ion }\end{array}$ & $\begin{array}{c}\text { Relative } \\
\text { evapotranspir } \\
\text { ation }\end{array}$ & $\begin{array}{c}\text { Relative } \\
\text { evapotranspi } \\
\text { ration }\end{array}$ \\
\hline $\begin{array}{c}\text { Independent } \\
\text { variable } 4\end{array}$ & Wettability & Wettability & Wettability & Wettability & Wettability & Wettability & Wettability \\
\hline $\begin{array}{c}\text { Independent } \\
\text { variable } 5\end{array}$ & Temperature & Temperature & Temperature & $\begin{array}{c}\text { Temperatur } \\
\mathrm{e}\end{array}$ & Temperature & Temperature & Temperature \\
\hline $\begin{array}{c}\text { Independent } \\
\text { variable } 6\end{array}$ & $\begin{array}{c}\text { 2017WFI- } \\
\text { NDVI }\end{array}$ & $\begin{array}{c}\text { 2017WFI- } \\
\text { NDVI }\end{array}$ & $\begin{array}{c}\text { 2017WFI- } \\
\text { NDVI }\end{array}$ & $\begin{array}{c}\text { 2017WFI- } \\
\text { NDVI }\end{array}$ & 2017WFI-NDVI & $\begin{array}{c}\text { 2017WFI- } \\
\text { NDVI }\end{array}$ & \\
\hline $\begin{array}{c}\text { Independent } \\
\text { variable } 7\end{array}$ & & & $\begin{array}{c}\text { 2018WFI- } \\
\text { NDVI }\end{array}$ & & & $\begin{array}{c}\text { 2018WFI- } \\
\text { NDVI }\end{array}$ & \\
\hline $\begin{array}{c}\text { Independent } \\
\text { variable } 8\end{array}$ & & & & & & & $\begin{array}{c}\text { 2017MODIS- } \\
\text { NDVI }\end{array}$ \\
\hline
\end{tabular}

Table 11. Experiment results of vegetation destruction capturing power of different models

\begin{tabular}{ccc}
\hline Model & Total area of waterfront greenway & Capturing power of vegetation destruction \\
\hline Multivariate linear regression model 1 & $325.7 \mathrm{~m}^{2}$ & 7 \\
\hline Multivariate linear regression model 2 & $325.7 \mathrm{~m}^{2}$ & 8 \\
\hline Multivariate linear regression model 3 & $325.7 \mathrm{~m}^{2}$ & 9 \\
\hline Multivariate linear regression model 4 & $325.7 \mathrm{~m}^{2}$ & 6 \\
\hline Multivariate linear regression model 5 & $325.7 \mathrm{~m}^{2}$ & 10 \\
\hline Multivariate linear regression model 6 & $325.7 \mathrm{~m}^{2}$ & 9 \\
\hline Multivariate linear regression model 7 & $325.7 \mathrm{~m}^{2}$ & 8 \\
\hline
\end{tabular}

Table 12. Experiments of vegetation destruction capturing ability of different methods

\begin{tabular}{cccc}
\hline Method & $\begin{array}{c}\text { Testing the area of vegetation } \\
\text { destruction in samples }\end{array}$ & $\begin{array}{c}\text { Practical inspection of } \\
\text { vegetation destruction area }\end{array}$ & $\begin{array}{c}\text { Capturing power of } \\
\text { vegetation destruction }\end{array}$ \\
\hline Spectral characteristics of vegetation & $25.46 \mathrm{~m} 2$ & $23.526 \mathrm{~m} 2$ & 6 \\
\hline Decision Tree Weak Classifier & $25.46 \mathrm{~m} 2$ & $22.48 \mathrm{~m} 2$ & 7 \\
\hline Vegetation extraction algorithm & $25.46 \mathrm{~m} 2$ & $21.88 \mathrm{~m} 2$ & 5 \\
\hline Manual threshold method & $25.46 \mathrm{~m} 2$ & $20.69 \mathrm{~m} 2$ & 6 \\
\hline Genetic algorithm & $25.46 \mathrm{~m} 2$ & $25.42 \mathrm{~m} 2$ & 9 \\
\hline
\end{tabular}

\section{References}

Ahmadybirgani H., Mcqueen K.G., Moeinaddini M., et al. (2017), Sand dune encroachment and desertification processes of the Rigboland Sand Sea, Central Iran, Scientific Reports, 27, 11523-11539.

Almada F., Francisco S.M., Lima C.S., et al. (2017), Historical gene flow constraints in a northeastern Atlantic fish: phylogeography of the ballan wrasse Labrus bergylta across its distribution range, Royal Society Open Science, 24, 1122111224.

Azmi F.M., Tajudin N.S., Shahari R. and Amri C.H.N.C. (2020), Early growth response and nutrients quality of fig (Ficus Carica L.) planted on bris soil effected by chicken manure amendments, Journal Clean Was, 4, 46-50.

Clifford N.C.M., Uko ED, Eze CL, Ari IT, Dorathy B. Umoetok and Allu A. U (2019), Ambient Seismic Noise Footprints And Spectra In The Middle Benue Trough, Nigeria, Earth Sciences Malaysia, 3, 23-31, DOI: 10.26480/esmy.02.2019.23.31 
Deymi-Dashtebayaz M and Kazemiani-Najafabad P. (2019), Energy, exergy, economic, and environmental analysis for various inlet air cooling methods on Shahid Hashemi-Nezhad gas turbines refinery, Energy \& Environment, 30, 481-498.

Emaminejad S., Gao W., Wu E., et al. (2017), Autonomous sweat extraction and analysis applied to cystic fibrosis and glucose monitoring using a fully integrated wearable platform, Proceedings of the National Academy of sciences of United States of America, 114, 14625-14630.

Emanuel JL, Ernest RM (2020),. Biochar as a feed additive for improving the performance of farm animals, Malaysian Journal of Sustainable Agriculture, 4, 86-93.

Govindan V.P. and Annamalai L. (2019),. Tetrameres Sp. (Spiruridae) from backyard chicken (Galliformes: Phasianidae) in Puducherry - A first report, Environmental Contaminants Reviews, 2, 15-16.

Graf A., Mcauley S.A., Sims C., et al. (2017), Moving toward a unified platform for insulin delivery and sensing of inputs relevant to an artificial pancreas, Journal of Diabetes Science and Technology, 11, 2308-2314.

Grezzana G.B., Moraes D.W., Stein A.T., et al. (2017), Impact of different normality thresholds for 24-hour ABPM at the primary health care level, Arquivos Brasileiros De Cardiologia 108, 11143-11148.

Kang L., Du H.L., Du X., Wang H.T., Ma W.L., Wang M.L. and Zhang F.B. (2018), Study on dye wastewater treatment of tunable conductivity solid-waste-based composite cementitious material catalyst, Desalination and Water Treatment, 125, 296-301.

Kanule J. and Ng'etich W. (2020), Numerical modeling of translational dynamics for shallow landslides based on flume tests - special case of spherical-cap-shaped slope sections, Geology, Ecology, and Landscapes, 4, 151-158.

Kumar D. (2017), Monitoring and assessment of land use and land cover changes (1977-2010) in Kamrup District of Assam, India using remote sensing and GIS techniques, Applied Ecology and Environmental Research, 15, 221-239.

Lehmann E., Fargues M., Dibié J.J.N., et al. (2017), Assessment of water resource contamination by pesticides in vegetableproducing areas in Burkina Faso, Environmental Science and Pollution Research, 25, 3121-3124.

Lisón F., Espín S., Aroca B., et al. (2017), Assessment of mercury exposure and maternal-foetal transfer in Miniopterus schreibersii (Chiroptera: Miniopteridae) from southeastern Iberian Peninsula, Environmental Science and Pollution Research, 24, 15497-15508.

Liu H. and Liu Z. (2010), Recycling utilization patterns of coal mining waste in China, Resources Conservation and Recycling, 54, 1331-1340.

Liu S.R., Sun H.Y., Liu H.Z., et al. (2019), Intelligent extraction method simulation of urban ecological restoration landscape layout characteristic, Computer Simulation, 36, 1201-1204.

Liu Z. (2018), Economic analysis of energy production from coal/biomass upgrading; Part 1: Hydrogen production, Energy Sources Part B-Economics Planning and Policy, 13, 132-136.

Liu Z. and Baghban A. (2017), Application of LSSVM for biodiesel production using supercritical ethanol solvent, Energy Sources Part A-Recovery Utilization and Environmental Effects, 39, 1869-1874.

Lu X., Zhang S., Chen X., et al. (2017), Ultrasensitive, highdynamic-range and broadband strain sensing by time-of-flight detection with femtosecond-laser frequency combs, Scientific Reports, 17, 13305-13309.

Malkoc A., Lin C., Probst D., et al. (2017), Towards the future development of an electrochemical continuous multimarker biosensor for enhanced glycemic management, Journal of Diabetes Science and Technology, 11, 19322-19367.

Mao S., Pu H., Chang J., et al. (2017), Ultrasensitive detection of orthophosphate ions with reduced graphene oxide/ferritin field-effect transistor sensors, Environmental Science Nano, 14, 1856-1863.

Mehl M.R. (2017), The Electronically Activated Recorder (EAR): A method for the naturalistic observation of daily social behavior, Current Directions in Psychological Science, 26, 21184-21190.

Olamilekan L.A. and Ogunbamowo P.O. (2019), Comparative heavy metal uptake and phytoremediation potential of three jatropha species, Environment \& Ecosystem Science, 3, 26-30.

Onamuti O.Y., Okogbue E.C. and Orimoloye I.R. (2017), Remote sensing appraisal of Lake Chad shrinkage connotes severe impacts on green economics and socio-economics of the catchment area, Royal Society Open Science, 24, 1711217119.

Oyekale A.S. (2017), Cocoa farmers' safety perception and compliance with precautions in the use of pesticides in centre and western Cameroon, Applied Ecology and Environmental Research, 15, 205-219.

Prabal B. and Rahman S.H. (2020), Aquatic health index of coastal aquaculture activities at south-eastern coast of Bang-ladesh, Water Conservation and Management, 4, 53-59.

Stefani F., Isabel N., Morency M.J., et al. (2018), The impact of reconstructed soils following oil sands exploitation on aspen and its associated belowground microbiome, Scientific Reports, 28, 12761-12798.

Ullah S. (2019), . A preliminary analysis of natural disasters, recent trends and future prospects in Pakistan and bordering countries: A review, Earth Sciences Pakistan, 2, 14-17

Wang H., Zhong H. and Bo G. (2018), Existing forms and changes of nitrogen inside of horizontal subsurface constructed wetlands, Environmental Science and Pollution Research, 25, 771-781.

Yevdokimov Y., Getalo V., Shukla D. and Sahin T. (2019), Measuring willingness to pay for electricity: The case of New Brunswick in Atlantic Canada, Energy \& Environment, 30, 292-303.

Zhang L., Goswami N., Xie J., et al. (2017), Unraveling the molecular mechanism of photosynthetic toxicity of highly fluorescent silver nanoclusters to Scenedesmus obliquus, Scientific Reports, 72, 16432-16467. 